\title{
Savoirs et fiction au Moyen Âge et à la Renaissance, sous la direction de Dominique BOUTET et Joëlle Ducos
}

\section{Paris}

\section{Maria Colombo Timelli}

\section{(2) OpenEdition}

1 Journals

\section{Édition électronique}

URL : https://journals.openedition.org/studifrancesi/11272

DOI : 10.4000/studifrancesi. 11272

ISSN : 2427-5856

Éditeur

Rosenberg \& Sellier

\section{Édition imprimée}

Date de publication : 1 avril 2018

Pagination : 110

ISSN : 0039-2944

\section{Référence électronique}

Maria Colombo Timelli, « Savoirs et fiction au Moyen Âge et à la Renaissance, sous la direction de Dominique воutet et Joëlle ducos Paris », Studi Francesi [En ligne], 184 (LXII | I) | 2018, mis en ligne le 29 juin 2018, consulté le 15 novembre 2021. URL : http://journals.openedition.org/studifrancesi/11272 ; DOI : https://doi.org/10.4000/studifrancesi. 11272

Ce document a été généré automatiquement le 15 novembre 2021.

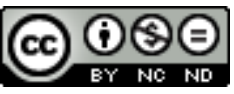

Studi Francesi è distribuita con Licenza Creative Commons Attribuzione - Non commerciale - Non opere derivate 4.0 Internazionale. 


\title{
Savoirs et fiction au Moyen Âge et à la Renaissance, sous la direction de Dominique BOUTET et Joëlle DUcos Paris
}

\author{
Maria Colombo Timelli
}

\section{RÉFÉRENCE}

Savoirs et fiction au Moyen Âge et à la Renaissance, sous la direction de Dominique BOUTET et Joëlle Ducos Paris, PUPS, 2015, 411 pp.

1 Nous signalons ici les articles portant sur le $\mathrm{XV}^{\mathrm{e}}$ siècle; pour les autres, on se reportera à la section «Medioevo».

Christine FERLAMPIN-ACHER (Le clerc, la beste et le lucidaire: merveilleux et savoir dans quelques romans féeriques en prose des $X I V^{e}$ et $X V^{e}$ siècles, pp. 43-58) fonde sa réflexion sur un corpus qui regroupe Perceforest, Artus de Bretagne (versions du $\mathrm{XIV}^{\mathrm{e}}$ et du $\mathrm{XV}^{\mathrm{e}}$ siècle), Isaïe le Triste, pour reconnaître les formes et les fonctions différentes que le savoir assume dans les romans féeriques à la fin du Moyen Âge: le discours savant peut en effet être inséré explicitement (par exemple dans certains discours englobant des notions médicales ou astrologiques), ou plus discrètement dans certaines inventions, surtout rattachées à la «merveille» (la «Beste glatissant» en fournit alors un des exemples les plus frappants). Cependant, une évolution est sensible $a u \mathrm{XV}^{\mathrm{e}}$ siècle, lorsque le savoir, tout en entrant dans l'invention narrative, peut être diabolisé voire devenir l'objet d'une parodie.

3 C'est plutôt au domaine épique que s'intéresse Dominique BOUTET (Savoirs géographiques et fictions épiques à la fin du Moyen Âge, pp. 59-71), en se concentrant sur Esclarmonde, une des suites de Huon de Bordeaux, le Myreur des histors de Jean d'Outremeuse, et Mabrien, mise en prose d'une chanson perdue. Selon des modalités variées, des sources savantes 
reconnaissables sont utilisées par les trois auteurs, parmi lesquelles la Lettre du prêtre Jean et le Livre de Jean de Mandeville. Témoins importants de l'évolution du genre épique entre $\mathrm{XIV}^{\mathrm{e}}$ et $\mathrm{XV}^{\mathrm{e}}$ siècle, les trois œuvres envisagées intègrent le savoir sur l'Orient: en combinant, chacune à sa manière, fictions littéraires et savoirs géographiques, elles nous éclairent sur les rapports «entre l'imaginaire et une réalité attestée par l'expérience contemporaine» (p. 71).

4 Agathe sultan examine Le Naufrage de la Pucelle de Jean Molinet, et en particulier la rencontre avec les sirènes, dans le cadre de la musicologie médiévale. Mélodie et chant s'y associent, ainsi que les «notes a havet» (crochetées) pour créer un effet mêlé de vérité et de fiction chez le lecteur (Note sur Jean Molinet: musique et fiction, pp. 221-232). 